\title{
PHYTOCHEMICAL ANALYSIS AND SUPPRESSION OF INFLAMMATORY TARGETS BY ADHATODA VASICA
}

\author{
AMALA REDDY, SUJATHA SUNDARESAN* \\ Department of Biotechnology, School of Bioengineering, SRM Institute of Science and Technology, Kattankulathur 603203 , \\ Kancheepuram, Tamil Nadu, India. Email: sujatha.sa@ktr.srmuniv.ac.in
}

Received: 13 December 2017, Revised and Accepted: 24 January 2018

\begin{abstract}
Objectives: A persistent and chronic inflammation may act as an underlying definition for many of the long-term illness such as diabetic foot ulcer, Alzheimer's disease and rheumatoid arthritis. Folklore medicinal plants provide immense health benefits with new remedies. Active compounds from plants containing alkaloids and phenolic compounds (flavonoids and tannins) possess antioxidant and anti-inflammatory activity. The leaves of Adhatoda vasica are most known for its effectiveness in treating respiratory diseases such as asthma, chronic bronchitis, and other respiratory conditions. In this report, we investigated the possible action of $A$. vasica against inflammation.
\end{abstract}

Methods: Solvents with varying polarity (Hexane, dichloromethane, ethyl acetate, and methanol) were used for the sequential extraction of leaves of A. vasica Linn (Family: Acanthaceae). The anti-inflammatory activity was assessed using simple in vitro methods. Phenols, flavonoids, phytosterols, saponins, alkaloids, and tannins were analyzed qualitatively using standard protocols. Anti-inflammatory activity was evaluated using albumin denaturation assay, membrane stabilization assay and proteinase inhibitory activity. Aspirin (diclofenac) was used as a standard drug for the study of anti-inflammatory activity.

Results: Our results substantiated that methanolic extract of $A$. vasica gave a maximum yield of $12.5 \%$ and apparently all bioactive phytochemical constituents were at a higher concentration in the methanolic extract. Methanolic extract of $A$. vasica showed a significant inhibition of the heatinduced albumin denaturation, red blood cells membrane stabilization, and proteinase inhibitory effects with $86 \pm 1.46,88 \pm 1.24$, and $96 \pm 0.93 \%$ for $1000 \mu \mathrm{g} / \mathrm{ml}$, respectively.

Conclusion: The above results delineate that the bioactive components were extracted using high polar solvent are mostly flavonoids and related polyphenols. These compounds may be the active constituents to render the anti-inflammatory activity to $\mathrm{A}$. vasica.

Keywords: Adhatoda vasica, Diclofenac, Anti-inflammatory, Red blood cells membrane stabilization, Albumin denaturation, Flavonoids.

(C) 2018 The Authors. Published by Innovare Academic Sciences Pvt Ltd. This is an open access article under the CC BY license (http://creativecommons. org/licenses/by/4. 0/) DOI: http://dx.doi.org/10.22159/ajpcr.2018.v11i5.24243

\section{INTRODUCTION}

This inflammatory response occurring at the site of injury is responsible for initiating various biochemical signaling pathways. Harmful stimulus like pathogens and the dead cells initiates protective responses which involve the immune cells, blood vessels and the various molecular mediators. Inflammation leads to recruitment of macrophages and mast cells to the site of injury and leads to the tissue repair. Medicinal plants and their extracts provide boundless benefits with diverse remedies [1]. Medicinal plants are easily available and have minimal side effects and enhance efficacy compared to the pre-existing drugs commercially available. Anti-inflammatory and antioxidants are potent biological activities of the plant extract [2,3]. Terpenoids, phenolic compounds such as phenolic acids, flavonoids, and tannins with varying polar nature is also responsible for the biological activity.

Chronic and persistent inflammation might be the elemental explanation of the long-term diseases such as rheumatoid arthritis, diabetic foot ulcers, and Alzheimer disease. The aggravation of the mediators such as the cytokines and growth factors may sometimes benefit or damage the process of inflammation which might be the cause of tissue deterioration which is otherwise a normal process.

In the present scenario, both steroidal anti-inflammatory and nonsteroidal anti-inflammatory (NSAIDs) drugs are being administered for treating inflammation. The steroids and NSAIDs have a great impact in treating inflammation, but their side effects outweigh their ability to reduce inflammation and thus they are used only for a short span of time. Thus, there has been a crusade for finding new drugs with minimal side effects $[4,5]$

Adhatoda vasica Nees, an evergreen shrub found in India and throughout various parts of the world belongs to the family of Acanthaceae and is commonly referred as Adosa. This plant as a whole or the extracts from its parts finds varied application in traditional medicine. The extract obtained from this plant has proven to be useful in treating various respiratory ailments such as asthma, chronic bronchitis, and other chronic ailments. The extract obtained from the boiling of the leaves is used in the treatment of rheumatoid arthritis and urinary tract infections. The diverse geographical variations are responsible for the difference in the phytochemical constituent present in the plants with diversified hypoglycemic effect, which is par with the anti-inflammatory modulation efficacy of the plant as well. Our current study is to evaluate the anti-inflammatory potential of the various extracts of $A$. vasica in vitro using simple laboratory techniques.

\section{METHODS}

Plant authentication and preparation of extract

The plant specimen has been collected from the botanical garden, Chennai, India. Botanical identification was performed by Prof. P. Jayaraman, Director, Plant Anatomy Research Centre, Chennai, India (Ref. no. PARC/2017/3360). An authenticated voucher specimen has been submitted for reference.

Leaves were collected, washed in distilled water and allowed to shade dry. The dried material was homogenized in the domestic mixture into 
a fine powder. The dried leaf powder (100 g) was extracted sequentially using various solvents in increasing order of polarity (hexane, dichloromethane [DCM], ethyl acetate [EA], and methanol) and was concentrated using reduced pressure under vacuum. Dried extracts were used for the further study.

\section{Drugs and chemicals}

The chemicals and solvents utilized for the study were obtained from SIGMA-ALDRICH and were of analytical grade.

\section{Yield of various extracts}

The various extracts obtained from sequential extraction were dried under reduced pressure and weighed [6,7]. The yield was calculated using the following formula.

Percentage yield $=\frac{\text { Weight of the sample extract obtained }(\mathrm{g})}{\text { Weight of the powdered sampled used }(\mathrm{g})} \times 100$

\section{Phytochemical analysis}

All phytochemical analysis was carried out using standard protocol [8].

1. Detection of alkaloids: Each extract was separately dissolved in Dilute Hydrochloric acid and filtered. Mixed well and $1 \mathrm{ml}$ filtrate was used as a sample for further experimentation analysis.

a. Mayer's test: Individual filtrates were treated with Mayer's reagent (potassium mercuric iodide). Formation of a yellow color precipitate after the addition of reagent along the sides of the test tube indicates the presence of alkaloids.

b. Wagner's test: Individual filtrates were treated with Wagner's reagent (iodine in potassium iodide). Formation of brown or reddish precipitate along the rim of the tubes indicates the presence of alkaloids.

c. Dragendorff's test: Individual filtrates were treated with Dragendorff's reagent (solution of potassium bismuth iodide). Formation of red precipitate inside the tube immediately after the addition of reagent indicates the presence of alkaloids.

2. Detection of carbohydrates: $5 \mathrm{mg}$ of the dried extracts were dissolved individually in $5 \mathrm{ml}$ of distilled water and filtered. $1 \mathrm{ml}$ of filtrate was used to detect the presence of carbohydrates.

a. Molisch's test: Individual filtrates were treated with drops of alcoholic $\alpha$-naphthol solution along the sides of a test tube. Formation of a violet ring at the interfacial junction indicates the presence of carbohydrates.

b. Benedict's test: Individual filtrates were treated with Benedict's reagent and heated gently. Formation of brick red precipitate indicates the presence of reducing sugars like aldehydes.

3. Detection of saponins

Froth test: Individual extracts were diluted with $20 \mathrm{ml}$ of distilled water and shaken in measuring cylinder for $15 \mathrm{~min}$, the formation of a thick layer of foam between 0.5 and $1 \mathrm{~cm}$ indicates the presence of saponins.

4. Detection of phytosterols

Salkowski's test: Individual filtrates were treated with chloroform and filtered. The filtrates were treated with few drops of concentrated sulfuric acid, shaken and allowed to settle. A golden yellow color formation indicates the presence of triterpenes.

5. Detection of phenols

Ferric chloride test: Individual filtrates were treated with 3-4 drops of ferric chloride solution. Formation of bluish black color indicates the presence of phenolic compounds.

6. Detection of tannins

Gelatin test: To each of the extract, $1 \%$ gelatin solution containing sodium chloride was added. Formation of white precipitate indicates the presence of tannins.

7. Detection of flavonoids

a. Alkaline reagent test: To $5 \mathrm{mg} / \mathrm{ml}$ of extracts, few drops of sodium hydroxide solution were added. Formation of yellow color precipitate, which turns colorless on the addition of dilute acid, shows the presence of flavonoids. b. Lead acetate test: To $5 \mathrm{mg} / \mathrm{ml}$ concentration of extracts a few drops of lead acetate solution was added. Formation of yellow color precipitate indicates the presence of flavonoids.

\section{In vitro anti-inflammatory assays}

Inhibition of albumin denaturation

The reaction mixture consisted of $0.2 \mathrm{~mL}$ of hen's egg albumin. Phosphate buffered saline and $(0.8 \mathrm{ml})$ and $2 \mathrm{ml}$ of varying concentration of extracts of A.vasica was added so the final concentration becomes 31.25, 62.5, $125,250,500$, and $1000 \mu \mathrm{g} / \mathrm{mL}$. The same volume of distilled water was taken as control. The samples were incubated at $37^{\circ} \mathrm{C}$ for $20 \mathrm{~min}$ and then again incubated at $70^{\circ} \mathrm{C}$ for $25 \mathrm{~min}$. After cooling the tubes were placed in running water and the absorbance was measured at $660 \mathrm{~nm}$ using the spectrophotometer. Diclofenac sodium or aspirin at the final concentration as that of the extracts was used as reference drug. All experiments were performed in triplicates $[9,10]$. Percent inhibition of protein denaturation was calculated using the following formula:

Percentage inhibition $=$ (Absorbance of control/absorbance of sample -1$) \times 100$

\section{Membrane stabilization assay}

Preparation of red blood cells (RBCs) suspension

About $10 \mathrm{ml}$ of whole human blood was collected and transferred to heparinized tubes. The tubes were then subjected to centrifugation at $3000 \mathrm{rpm}$ for $10 \mathrm{~min}$, and the resultant pellet was washed 3 times with equal volume of normal saline. The volume of the RBC was measured and reconstituted to $10 \% \mathrm{v} / \mathrm{v}$ suspension using normal saline [11].

\section{Heat-induced hemolysis-HRBC membrane stabilization assay}

About $1 \mathrm{ml}$ of RBC suspension was mixed with $1 \mathrm{ml}$ of various extracts of $A$. vasica. The control tube comprised $1 \mathrm{ml}$ of RBC suspension with normal saline. Diclofenac sodium/aspirin was taken as a standard drug. The entire set of centrifuge tubes containing reaction mixture was incubated at $56^{\circ} \mathrm{C}$ for 30 min covered with aluminum foil. This was then cooled under running tap water. The reaction mixture was subjected to centrifugation at $2500 \mathrm{rpm}$ for $5 \mathrm{~min}$. The optical density of the supernatant was measured at $560 \mathrm{~nm}$ [12]. The experiment was performed in triplicates.

$\%$ Membrane stabilization activity $=($ Absorbance of test $/$ absorbance of control) $\times 100$

$\%$ Hemolysis $=100-\{($ Absorbance of test $/$ absorbance of control $) \times 100\}$

\section{Proteinase inhibitory action}

The reaction mixture consisted of $1 \mathrm{ml}$ of $20 \mathrm{mM}$ Tris $\mathrm{HCl}$ buffer at a pH 7.4, $0.06 \mathrm{mg}$ trypsin and $1 \mathrm{ml}$ of various extracts of $A$. vasica [13]. The mixture was incubated at $37^{\circ} \mathrm{C}$ for $5 \mathrm{~min}$ and then $1 \mathrm{ml}$ of $0.8 \%(\mathrm{w} / \mathrm{v})$ casein was added [14]. This reaction mixture was again incubated at room temperature for about $20 \mathrm{~min}$. Finally, the reaction was terminated by the addition of $2 \mathrm{ml}$ of $70 \%$ perchloric acid. This mixture was vortexed, and the absorbance of the supernatant was measured at $210 \mathrm{~nm}$ [15]. The experiment was performed in triplicates. The percentage inhibition of proteinase inhibitory activity was calculated using the formula below:

Percentage inhibition $=($ Absorbance of test $/$ absorbance of control -1$) \times 100$

\section{RESULTS}

\section{Extraction of plant material}

The extracts obtained by sequential extraction have shown considerable differences (Table 1). In the extraction, maximum yield was obtained in the methanolic extract, followed by EA and hexane (least polar solvent). DCM did not show any considerable yield.

\section{Phytochemical screening}

The preliminary phytochemical tests indicated the presence of phytosterols, carbohydrates, alkaloids, phenols, saponins, 
tannins, and flavonoids in various extracts of $A$. vasica $[16,17]$. The phytochemical constituents were tabulated for all the extracts (Table 2).

\section{(Albumin denaturation assay}

Methanolic extract was the most effective in inhibiting heat-induced albumin denaturation as shown in Table 3. Inhibition of up to $86 \pm 1.46 \%$ at $1000 \mu \mathrm{g} / \mathrm{ml}$ of methanolic extract was observed. Aspirin, a standard anti-inflammatory drug [18] showed the maximum inhibition $(88 \pm 1.22 \%)$ at $1000 \mu \mathrm{g} / \mathrm{ml}$.

\section{Membrane stabilization assay}

Test extract $(31.25-1000 \mu \mathrm{g} / \mathrm{ml})$ showed a possible membrane stabilization potency of RBCs to varying degree as shown in Table 4.

Table 1: \% of Yield of various extracts of $A$. vasica

\begin{tabular}{lll}
\hline Extracts & Yield (gram) & Yield\% \\
\hline Hexane & $1.4 \pm 1.455$ & 1.4 \\
DCM & $0.6 \pm 0.975$ & 0.6 \\
EA & $7.7 \pm 0.955$ & 7.7 \\
Methanol & $12.5 \pm 2.237$ & 12.5 \\
\hline
\end{tabular}

Each value represents average of three analysis \pm SD. A. vasica: Adhatoda vasica, DCM: Dichloromethane, EA: Ethyl acetate

Table 2: Phytochemical constituents of various extracts of A. vasica

\begin{tabular}{lllll}
\hline Phytochemicals & Hexane & DCM & EA & Methanol \\
\hline Alkaloids & + & $\sqrt{ }$ & + & ++ \\
Carbohydrates & + & + & + & ++ \\
Saponins & + & + & + & ++ \\
Phytosterols & + & + & + & ++ \\
Phenols & + & $\sqrt{ }$ & + & ++ \\
Tannins & - & - & - & - \\
Flavonoids & - & - & + & ++ \\
\hline
\end{tabular}

Presence (+), high concentration (++), absence $(-)$ and trace amount $(\sqrt{ })$ of phytochemicals. A. vasica: Adhatoda vasica, DCM: Dichloromethane, EA: Ethyl acetate
Methanolic extract showed the maximum stabilization $(88 \pm 1.24 \%$ at $1000 \mu \mathrm{g} / \mathrm{ml}$ ). Aspirin, the standard drug showed the maximum inhibition, $92 \pm 0.05$ at $1000 \mu \mathrm{g} / \mathrm{ml}$.

\section{Proteinase inhibitory activity}

Various extracts of $A$. vasica exhibited significant anti-proteinase activity at different concentrations as shown in Table 5. Methanolic extract showed maximum inhibition of $86 \pm 0.93 \%$ at $1000 \mu \mathrm{g} / \mathrm{ml}$. Aspirin showed the maximum inhibition $(96 \pm 0.075 \%)$ at $1000 \mu \mathrm{g} / \mathrm{ml}$.

\section{DISCUSSION}

Among the seven phytochemical tests conducted, five tests gave positive results with respect to all the extracts [19]. Tannins were lacking in all the extracts obtained. Majority of the bioactive compounds were present in methanolic extracts at a higher concentration in comparison with that of EA extract. Flavonoids were present only in extracts with high polar solvents such as EA and methanol [20]. DCM extract contains only trace amounts of bioactive constituents in comparison with all other extracts. Fundamental structural integrity and functional damage to proteins could either modify or denature the proteins [21]. The sequence of denaturation is evidenced in inflammation and needs to be carefully monitored [18]. Diclofenac sodium or aspirin is a widely accepted anti-inflammatory drug which showed dosedependent capability to stabilize thermally-induced protein denaturation [22]. As a part of our investigation on the mechanism of potent anti-inflammatory activity, the ability of various extracts of $A$. vasica to inhibit protein degradation were studied. Phagocytic nature of neutrophil is due to the lysosomal constituents, which includes suicidal bags or enzymes such as proteases which acts against bacteria, yet on extracellular release into the neighboring tissue, it can cause acute inflammation and damage [23]. RBCs membranes are accepted to mimic the chemical constituent of neutrophils; therefore, stabilization of the RBCs membrane model was studied to understand the mechanism of anti-inflammatory of A. vasica [24]. In this context, the methanolic extract was found to efficient in inhibiting the heat-induced hemolysis. Thus, the membrane stabilization depicted to be an effective mechanism for understanding the anti-inflammatory effect. Thus methanolic

Table 3: Effect of various extracts of $A$. vasica on albumin denaturation

\begin{tabular}{|c|c|c|c|c|c|}
\hline \multirow[t]{2}{*}{ Concentration in $\mu \mathrm{g}$} & \multicolumn{5}{|c|}{$\%$ Inhibition } \\
\hline & Hexane & DCM & EA & Methanol & Diclofenac \\
\hline 31.25 & $17 \pm 0.095$ & $24 \pm 1.22$ & $65 \pm 1.45$ & $63 \pm 1.33$ & $74 \pm 0.92$ \\
\hline 62.5 & $18 \pm 0.56$ & $26 \pm 2.24$ & $66 \pm 0.46$ & $64 \pm 0.84$ & $84 \pm 0.56$ \\
\hline 125 & $25 \pm 0.75$ & $36 \pm 1.15$ & $75 \pm 0.82$ & $74 \pm 0.75$ & $83 \pm 1.45$ \\
\hline 250 & $26 \pm 2.23$ & $37 \pm 0.88$ & $77 \pm 0.56^{*}$ & $76 \pm 0.34^{*}$ & $83 \pm 1.67$ \\
\hline 500 & $41 \pm 0.42$ & $55 \pm 0.77$ & $84 \pm 0.95^{*}$ & $84 \pm 1.78^{*}$ & $85 \pm 1.34$ \\
\hline 1000 & $47 \pm 1.78$ & $37 \pm 0.99$ & $85 \pm 0.75^{*}$ & $86 \pm 1.46^{*}$ & $88 \pm 1.22$ \\
\hline
\end{tabular}

Egg albumin was treated with indicated concentrations of the extracts, and percentage inhibition of protein denaturation was calculated. Data represent mean \pm SD from three individual experiments, ${ }^{*} \mathrm{P}<0.05$ as compared with the respective concentrations of the other extracts. EA: Ethyl acetate, A. vasica: Adathoda vasica, DCM: Dichloromethane

Table 4: Effect of various extracts of $A$. vasica on HRBC stabilization

\begin{tabular}{|c|c|c|c|c|c|}
\hline \multirow[t]{2}{*}{ Concentration in $\mu \mathrm{g}$} & \multicolumn{5}{|c|}{$\%$ Stabilization } \\
\hline & Hexane & DCM & EA & Methanol & Diclofenac \\
\hline 31.25 & $22 \pm 1.04$ & $33 \pm 0.099$ & $61 \pm 0.55$ & $61 \pm 1.44$ & $73 \pm 2.33$ \\
\hline 62.5 & $32 \pm 1.30$ & $45 \pm 1.34$ & $65 \pm 0.62$ & $66 \pm 0.97$ & $84 \pm 1.33$ \\
\hline 125 & $35 \pm 1.32$ & $45 \pm 1.42$ & $71 \pm 0.88$ & $72 \pm 0.07$ & $85 \pm 0.92$ \\
\hline 250 & $40 \pm 0.072$ & $46 \pm 2.34$ & $73 \pm 1.77^{*}$ & $76 \pm 0.07^{*}$ & $86 \pm 1.23$ \\
\hline 500 & $51 \pm 0.091$ & $55 \pm 1.66$ & $75 \pm 1.34^{*}$ & $82 \pm 1.77^{*}$ & $90 \pm 1.45$ \\
\hline 1000 & $53 \pm 0.095$ & $58 \pm 2.33$ & $75 \pm 1.45^{*}$ & $88 \pm 1.24 *$ & $92 \pm 0.05$ \\
\hline
\end{tabular}

RBCs suspensions were treated with indicated concentrations of the extracts and represented as percentage stabilization of RBCs membrane as tabulated. Data represent mean $\pm \mathrm{SD}$ from three individual experiments ${ }^{*} \mathrm{p}<0.05$ as compared with the respective concentrations of the other extracts. EA: Ethyl acetate, A. vasica: Adhatoda vasica, DCM: Dichloromethane, HRBC: Hemolysis red blood cells 
Table 5: Effect of various extracts of $A$. vasica on proteinase inhibition

\begin{tabular}{llllll}
\hline Concentration in $\boldsymbol{\mu g}$ & \multicolumn{2}{l}{ \% Inhibition } & & & \\
\cline { 2 - 6 } & Hexane & DCM & EA & Methanol & Diclofenac \\
\hline 31.25 & $22 \pm 1.34$ & $33 \pm 0.95$ & $64 \pm 0.33$ & $65 \pm 0.75$ & $84 \pm 0.95$ \\
62.5 & $32 \pm 1.76$ & $36 \pm 0.87$ & $67 \pm 0.71$ & $71 \pm 0.65$ & $85 \pm 1.87$ \\
125 & $33 \pm 2.44$ & $45 \pm 1.45$ & $72 \pm 1.87^{*}$ & $78 \pm 0.97^{*}$ & $85 \pm 1.56$ \\
250 & $45 \pm 1.87$ & $54 \pm 1.33$ & $73 \pm 0.08^{*}$ & $80 \pm 1.35^{*}$ & $87 \pm 1.45$ \\
500 & $46 \pm 1.67$ & $52 \pm 1.67$ & $78 \pm 1.54^{*}$ & $85 \pm 1.87^{*}$ & $95 \pm 0.92$ \\
1000 & $47 \pm 1.77$ & $64 \pm 0.87$ & $82 \pm 1.33^{*}$ & $86 \pm 0.93^{*}$ & $96 \pm 0.075$ \\
\hline
\end{tabular}

Casein was added with trypsin and treated with indicated concentrations of the extracts, and percentage inhibition of proteinase activity was tabulated. Data represent mean \pm SD from three individual experiments, ${ }^{*} \mathrm{p}<0.05$ as compared with the respective concentrations of the other extracts. EA: Ethyl acetate, $A$. vasica: Adhatoda vasica, DCM: Dichloromethane

extract possibly maintains the integrity of the membrane to prevent the release of the lysosomal content of neutrophils into the extracellular environment. Thus, the membrane stabilization may be established by creating a difference in hypotonic nature which led to the shrinkage of the cell membrane [25]. In a pathophysiological condition like diabetes, tissue damage due to a decrease in the production of proteinase inhibitors could lead to necrosis and finally amputation [26-31]. This could be due to prolonged inflammation which is mainly done by matrix metalloproteinases which are responsible for the degradation of the extracellular matrix. Thus, extract of $A$. vasica may depict to be an effective proteinase inhibitor which can combat the proteolytic enzymes that could develop tissue damage during inflammation.

\section{CONCLUSION}

The present study revealed the anti-inflammatory activity of $A$. vasica Linn using simple lab techniques. The presence of secondary metabolites such as alkaloids, flavonoids, and related polyphenols might be responsible for its activity. Further investigations are to be delineated to identify the active components in A. vasica and substantiate the signaling mechanism behind its anti-inflammatory efficacy.

\section{CONFLICTS OF INTEREST}

There is no conflict of interest.

\section{REFERENCES}

1. Jayasri MA, Gunasekaran S, Radha A, Mathew T. Anti-diabetic effect of Costus pictus leaves in normal and streptozotocin-induced diabetic rats. Int J Diabetes Metab 2008;16:117-22.

2. Madduluri S, Sitaram B, Balasekharan C. In vitro evaluation of antiinflammatory activity of methanolic and ethanolic leaf extracts of five indigenous plants in south India. Int J PharmTech Res 2014;6:569-74.

3. Patel VR, Patel PP, Kujal SS. Antioxidant activity of some selected medicinal plants in western region of India. Adv Biol Res 2010;4:23-6.

4. Ncube NS, Afolayan AJ, Okoh AI. Assessment techniques of antimicrobial properties of natural compounds of plant origin: Current methods and future trends. Afr J Biotechnol 2008;7:1797-806.

5. Nemudzivhadi V, Masoko P. In vitro assessment of cytotoxicity, antioxidant, and anti-inflammatory activities of Ricinus communis (Euphorbiaceae) leaf extracts. Evid Based Complement Alternat Med 2014;2014:625961.

6. Jayasri MA, Gunasekaran S, Radha A. Anti-denaturation and antioxidant activity of Annona cherimola-in vitro. Int J Pharm BioSci 2001:2:222-38.

7. Quettier-Deleu C, Gressier B, Vasseur J, Dine T, Brunet C, Luyckx M, et al. Phenolic compounds and antioxidant activities of buckwheat (Fagopyrum esculentum moench) hulls and flour. J Ethnopharmacol 2000;72:35-42.

8. Singleton VL, Orthofer R, Lamuela-raventos RM. Analysis of total phenols and other oxidation substrates and antioxidants by means of folin-ciocalteu reagent. Methods Enzymol 1999;299:152-78.

9. Boakye-Gyasi E, Woode E, Ainooson GK, Obiri DD, Ansah C, Duwejua M, et al. Anti-Inflammatory and antipyretic effects of an ethanolic extract of Palisota hirsuta K. schum roots. Afr J Pharm Pharmacol 2008;2:191-9.
10. Shinde UA, Phadke AS, Nari AM, Mungantiwar AA, Dikshit VJ, Saraf MN. Membrane stabilization activity-a possible mechanism of action for the anti-inflammatory activity of Cedrus deodara wood oil. Fitoterapia 1999;70:251-7.

11. Kang S, Cho S, Chung JH, Hammerberg C, Fisher GJ, Voorhees JJ. Inflammation and extracellular matrix degradation mediated by activated transcription factors nuclear factor- $\kappa \mathrm{B}$ and activator protein-1 in inflammatory acne lesions in vivo. Am J Pathol 2005;166:1691-9.

12. Sadique J, Al-Rqobahs WA, Bughaith, EL-Gindi AR. The bioactivity of certain medicinal plants on the stabilization of RBC membrane system. Fitoterapia 1989;60:525-32.

13. Anosike CA, Obidoa O, Ezeanyika LU. Membrane stabilization as a mechanism of the anti-inflammatory activity of methanol extract of garden egg (Solanum aethiopicum). Daru 2012;20:76.

14. Shiny CT, Saxena A, Gupta SP. Phytochemical and hypoglycaemic activity investigation of Costus pictus plants from Kerala and Tamil Nadu. Int J Pharm Sci Invent 2013;2:11-8.

15. Sakat S, Juvekar AR, Gambhir MN. In vitro antioxidant and antiinflammatory activity of methanol extract of Oxalis cornicula Linn. Int J Pharm Pharmacol Sci 2010;2:146-55.

16. Tiwari P, Kumar B, Kaur M, Kaur G, Kaur H. Phytochemical screening and extraction: A review. Int Pharm Sci 2011;1:324-33.

17. Das K, Tiwari RS, Shrivastava DK. Techniques for evaluation of medicinal plant products as antimicrobial agent: Current methods and future trends. J Med Plants Res 2010;4:104-11.

18. Yonathan M, Asres A, Assefa K, Bucar F. In vivo anti-inflammatory and anti-nociceptive activities of Cheilanthes farinose. J Ethnopharmacol 2006;108:462-70.

19. Shivshankar MG, Shanmugarajan TS. In vitro potential of plant stress hormone methyl jasmonate for anti-arthritis, anti-inflammatory and free radical scavenging activity 2015. Int J Pharm Tech Res 2014;8:161-7.

20. Handa SS, Khanuja SP, Longo G, Rakesh DD. Extraction Technologies for Medicinal and Aromatic Plants. Trieste: International Centre for Science and High Technology; 2008. p. 21-5.

21. Jasmine R, Rajasulochana M, Aude R. Evaluation of in vitro antioxidant and anti-inflammatory property exhibited by silver nanoparticles stabilized by adathoda vasica. J Chem Pharm Res 2016;8:128-37.

22. Mizushima Y, Kobayashi M. Interaction of anti-inflammatory drugs with serum proteins, especially with some biologically active proteins. J Pharm Pharmacol 1968;20:169-73.

23. Shayoub ME, Dawoud A, Dawoud H. Phytochemical analysis of leaves extract of Eucalyptus camaldulensis Dehnh. Omdurman J Pharm Sci 2015;2:64-72.

24. Huda-Faujan N, Noriham A, Norrakiah AS, Babji AS. Antioxidant activity of plants methanolic extracts containing phenolic compounds. Afr J Biotechnol 2009;8:484-9.

25. Masoko P, Eloff JN. Screening of twenty-four South African combretum and six Terminalia species (Combretaceae) for antioxidant activities. Afr J Tradit Complement Altern Med 2006;4:231-9.

26. Soni R, Srivastava M. Effect of ethanolic extract of Cinnamomum tamala leaves on wound healing in STZ induced diabetes in rats. Asian J Pharm Clin Res 2013;6:39-42.

27. Reddy SS, Raju B, Sridhar C. Novel pyrazolines: Synthesis and evaluation of their derivatives with anticancer and anti-inflammatory activities. Int J Pharm Pharm Sci 2016;8:247-54.

28. Lodhi S, Vadnere G. Relevance and perspectives of experimental wound models in wound healing research. Int J Pharm Pharm Sci 2017;10:265-73. 
29. Bains A, Tripathi A. Evaluation of antioxidant and anti-inflammatory properties of aqueous extract of wild mushrooms collected from Himachal Pradesh. Asian J Pharm Clin Res 2017;10:467-72.

30. Annavarapu TR, Renuka P, Akhil P, Divya P, Priyanka D. Evaluation of the anti-inflammatory activity of combination of ethanol extracts of Azadirachta indica (neem) and Lawsonia inermis, (henna). Asian J Pharm Clin Res 2016;9:256-8.

31. Bhandary S, Sehgal A, Rao L, Rao K, Kusumgar P, Thanusubramanian H. Bilateral blindness due to anti-tubercular treatment: A rare presentation. Asian J Pharm Clin Res 2016;9:1-2. 